\title{
Industrial Design and Application of A Railway Electric Special Power Supply
}

\author{
Peng Yao and Zhiwei Zhu
}

\begin{abstract}
The newly constructed railway on the plateau (remote and depopulated area) were facing a very practical problem that the railway electric distribution supply system (EDSS) cannot find the public power supply. The conventional solutions suffer from the problems of the huge cost and construction difficulties. Therefore, the topology, industrial design and control of railway electric special power supply (RESPS) are proposed in this paper for cost-effectively supporting power to EDSS. Regarding to potential over-current driver fault caused by EDSS load, a piecewise linear PI control strategy is proposed to improve the continuous operation capability of the inverter once inrush current occurred . To verify the proposed RESPS, the simulation results and $27.5 / 10 \mathrm{kV}, 1000 \mathrm{kVA}$ RESPS field application tests are carried out to prove the feasibility of the RESPS. Finally, some depth thoughts that maybe helpful to the future development are summarized.
\end{abstract}

Index Terms - Field tests, industrial design, inrush current, piecewise linear, railway electric special power supply (RESPS).

\section{INTRODUCTION}

$\mathrm{R}$ AILWAY power system (RPS) includes railway traction power system (RTPS) and electric distribution supply system (EDSS). Generally, the power supply of the EDSS is provided by the public grid through the dedicated transmission line. However, in Nyingchi-Lhasa Railway, Golmud-Lhasa Railway and Golmud-Korla Railway, the power supplies of EDSS are extremely scarce. Conventionally, there is no choice that the dedicated power supply transmission line can only pass through the no-man's land, Gobi, Plateau [1] and even perennial frozen area [2]. Therefore, the construction is very costly and extremely difficult. Moreover, the important loads of EDSS such as railway signal equipment, disaster prevention warning system, station lighting [3], etc. must be reliably supplied. Therefore, it is of great significance to study the special power supply to solve the problems. Otherwise, the operation and cost-effective development of railway will be hindered.

Manuscript received August 27, 2020; revised November 9, 2020; accepted December 11, 2020. Date of publication December 30, 2020; date of current version December 20, 2020. This work was supported by Zhuhai IndustryUniversity-Research Cooperation Project.

Both authors are with the Zhuhai Wanlida Electrical Automation Co., Ltd. and Guangdong Province Voltage Sag Engineering Technology Research Center of Enterprise Power Supply \& Distribution System, Zhuhai, Guangdong, 519085, China (email: 353891290@qq.com).

Digital Object Identifier 10.24295/CPSSTPEA.2020.00026

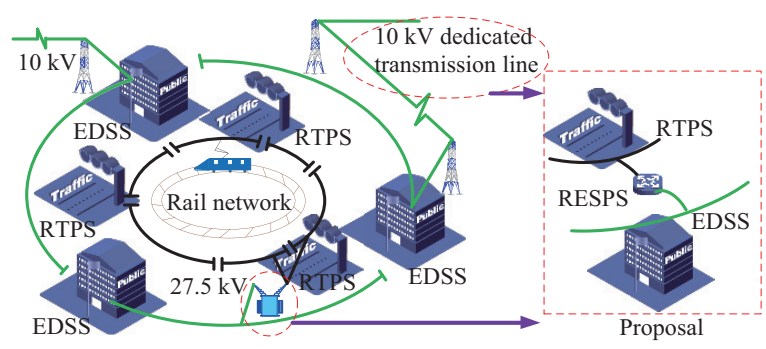

Fig. 1. Conventional and the Proposed Solution.

Traditionally, to solve the problems of insufficient power supply and huge cost, the power supply can actually obtain from the traction side by $27.5 / 10 \mathrm{kV}$ transformer as shown in Fig. 1. However, the power quality problems, such as voltage fluctuation, voltage unbalance, reactive power, and harmonics [4], [5] in RTPS are the headaches for engineers. In practical applications, wind power and photovoltaic power have been used as backup power supplies on the $0.4 \mathrm{kV}$ for low-voltage loads. However, they all have power fluctuations and are affected by the environment such as sunshine and seasons, so they cannot continuously provide a stable voltage and are restricted in applications.

Through the above problems, two aspects are considered: 1) From the perspective of a special power supply, the traction voltage $(27.5 \mathrm{kV})$ is converted into a high-voltage of $10 \mathrm{kV}$ as the off-grid voltage source. 2) From the perspective of an energy router, it connects RTPS and EDSS networks as a backbone router. In practical applications, the two aspects are combined with each other. Because the special power supply not only supplies to the load directly, but also supplies power to the EDSS network.

Therefore, in this paper, a Railway Electric Special Power Supply (RESPS) is proposed to distribute power to the EDSS as illustrated in Fig. 1. The purpose of the RESPS is to transform voltage from traction voltage (single-phase $27.5 \mathrm{kV}$ ) to three-phase high quality $10 \mathrm{kV}$.

Actually, in industrial field, many "Special Power Supplies (SPS)" have been studied by scholars and engineers according to the application purposes [6]-[13]. [14]-[18] introduce the converter topology in different voltage levels, multi-port interface, DC control principle, etc. In addition, the control strategies [19]-[23], mathematics models [21], [22] are researched. With the development of application, the research on energy routers is gradually increasing. [24]-[30] studied 
the scheme, control and development of common energy routers. In particular, [31]-[34] analyzed the application of energy routers in high-voltage and high-power applications. At present, the research about supply characteristics of special power supply or energy router both focused on powering a single dedicated load, not powering a load network.

In this paper, the proposed RESPS is for the high voltage and high power application, and the contributions of the paper can be summarized in below:

1) The structure and design method of the RESPS are proposed, and the $27.5 / 10 \mathrm{kV}, 1000 \mathrm{kVA}$ prototype are strictly conformed to actual parameters.

2) From the perspective of supplying power to the load network, a control method that improved the continuous operation capability of RESPS when inrush current occurred is proposed. And the control strategy is proposed for reducing the overcurrent driver fault caused by the voltage regulation while the inrush current.

3) A series of complex field application test were performed, including inrush current shock test (including simulation), dynamic load shock test, input and output voltage quality test, single phase grounding fault test and low voltage test on the prototype.

The main purpose of this article is to support the feasibility and effectiveness of RESPS. Furthermore, the paper aims to solve the problem that the inrush current generated by the load network causes the high-voltage inverter to stop running when the special power supply and energy router powering the load network. The remainder of the paper is organized as follows: In section II, the topology, the industrial designs and assembly of the RESPS are proposed and described in details. In section III, the overcurrent driver fault analysis and control strategy are proposed for complex functions of the RESPS. In section $\mathrm{IV}$, the different industrial field experiments and simulation are carried out for the RESPS in Turpan-Korla railway, China. Finally, some thoughts and conclusions are drawn in section V.

\section{The Topology of A 27.5/10 kV RESPS}

In order to meet the requirements of industrial application environment, the design principles of RESPS are summarized before the proposal:

1) The output voltage of the inverter should be relatively high. This can reduce the current and heat of the power device. At the same time, the current of inverter port will be lower when inrush current.

2) Topology (including control algorithms) allows normal operation when single phase grounding fault occurred on the output side.

3) The power unit is modularly mounted and designed for the dust environment on industrial site.

In this section, the topology of the RESPS is proposed in part $\mathrm{A}$ in terms of the design principles. And, the three major parts are discussed in prat $\mathrm{B}, \mathrm{C}$ and $\mathrm{D}$, respectively. At last, the key parameters and prototype assembling of the RESPS are given in part $\mathrm{E}$.

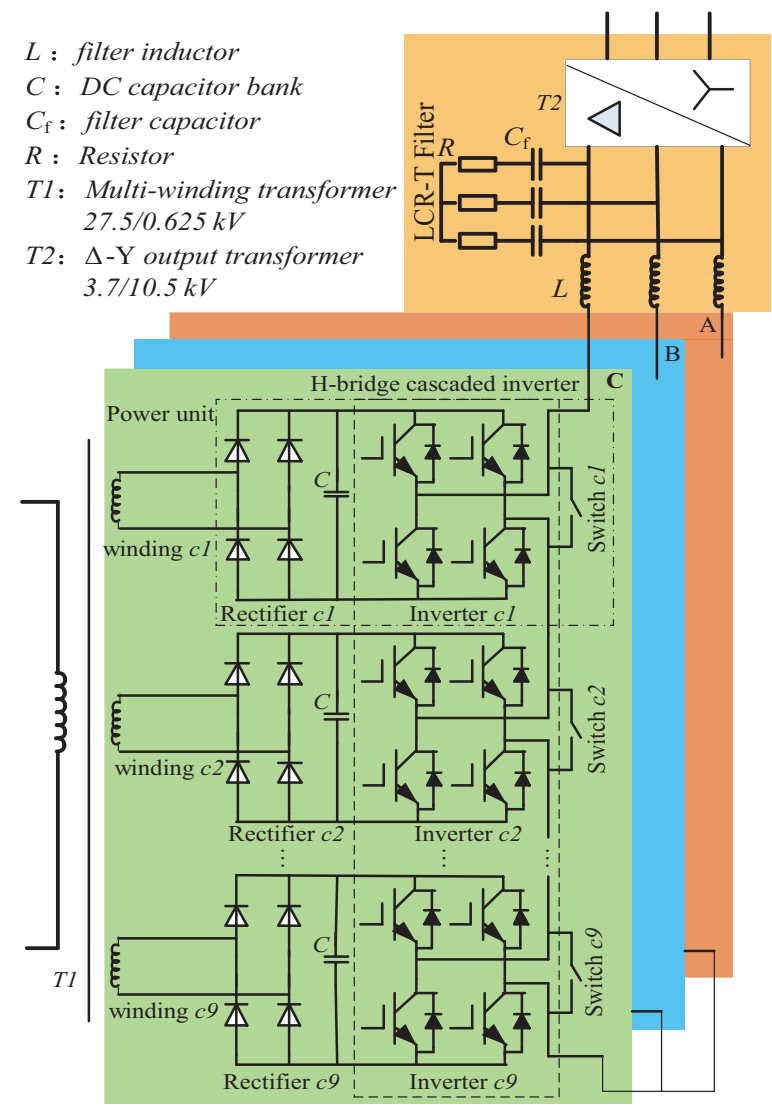

Fig. 2. Topology of the RESPS.

\section{A. 27.5/10 kV RESPS Topology}

As shown in Fig. 2, the proposed RESPS consists of multiwinding transformer, AC-DC-AC converter and LCR-T filter. The multi-winding transformer is designed to transform the single phase $27.5 \mathrm{kV}$ into multi low output voltage. Because of the low voltage level, the multi-winding transformer greatly reduces the required number of converter units (see part $\mathrm{C}$ ). Thus, the cost, control complexity, required sensors and drivers can be significantly reduced.

The purpose of the AC-DC-AC converter is to isolate voltage fluctuations and harmonics, and also transform the poor quality single-phase $\mathrm{AC}$ voltage to stable three-phase $\mathrm{AC}$ voltage.

And, LCR-T filter has two parts, namely: LCR and T transformer ( $\Delta-Y$ output transformer). The purpose of the LCR-T is to reduce high-order harmonic voltage produced by the AC-DC-AC converter, and allow current to flow through. And, the $\Delta-Y$ output transformer is to achieve electrical isolation between H-bridge cascaded inverter (see Fig. 2 ) and the loads.

\section{B. Multi-Winding Transformer}

The industrial prototype of the multi-winding transformer is provided in Fig. 3. Using the transformer, the voltage level of the power device in power unit can be reduced, and facilitates device selection and cost control. The output voltage of the 


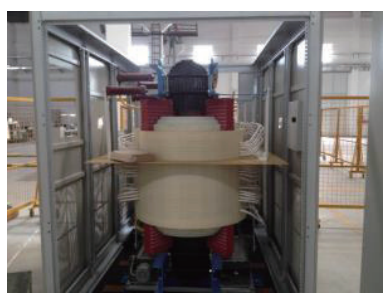

Fig. 3. The industrial prototype of Multi-winding Transformer.

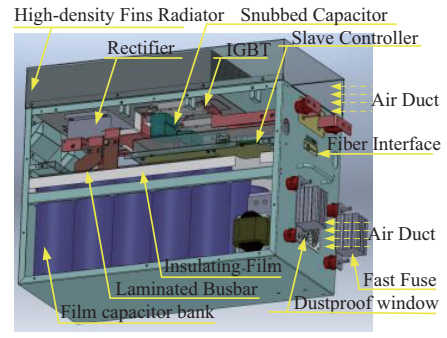

(a)

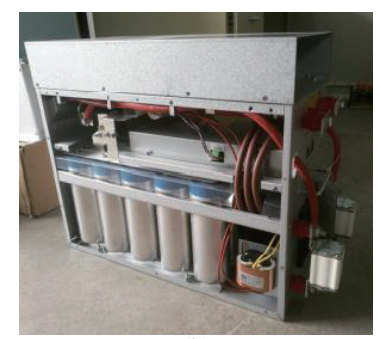

(b)
Fig. 4. Power unit: (a) 3D Model, and (b) industrial prototype.

multi-winding transformer has 28 low-voltage windings, 27 of which are $625 \mathrm{~V}$-windings connected to the units and the rest one is $240 \mathrm{~V}$ auxiliary winding for powering the control system.

In the design of transformer, the impedance between two windings should be the same to realizing the same voltage drop among the 27 windings. Particularly in the industrial design, the impedance deviation of each winding in the same position (winding $a 1, b 1$ and $c 1$ are considered to be at the same position in the magnetic circuit, the same to winding $a x, b x, c x$, $x=1 \cdots 9$ ) is less than $5 \%$ in production process.

In the industrial design, the multi-winding transformer is a core type transformer. Among them, the silicon steel sheet is a high-quality silicon steel sheet, and the winding is made of oxygen-free copper. The rated power frequency withstand voltage of the primary winding to the ground and the secondary winding is up to AC $85 \mathrm{kV}$.

\section{C. $A C-D C-A C$ Converter}

The AC-DC-AC converter consists of 27 power units. On the input side, each power unit connects to the low voltage side of the multi-winding transformer. On the output side, the power unit forms the H-bridge cascaded inverter as shown in Fig. 2. At the same time, every power unit has an uncontrolled rectifier, matrix film capacitor bank, H-bridge inverter and bypass switch.

The power unit 3D model and industrial prototype are illustrated in Fig. 4. As shown in Fig. 4(a), the power unit is designed in a layered manner. The top layer consists of highdensity fins radiator and its heat dissipation air duct. The bottom layer is matrix film capacitor bank and a small air duct that passes through a dustproof window. The top layer and the bottom layer are separated into a relatively closed intermediate layer. Rectifier, IGBTs, drivers and slave controller are arranged in the intermediate layer.

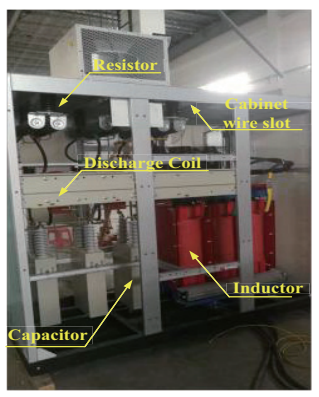

(a)

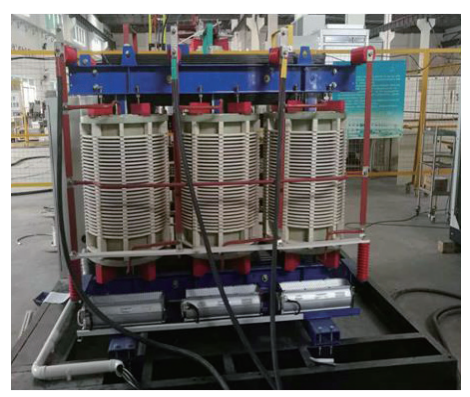

(b)
Fig. 5. Industrial prototype: (a) LCR, and (b) $\Delta-Y$ output transformer.

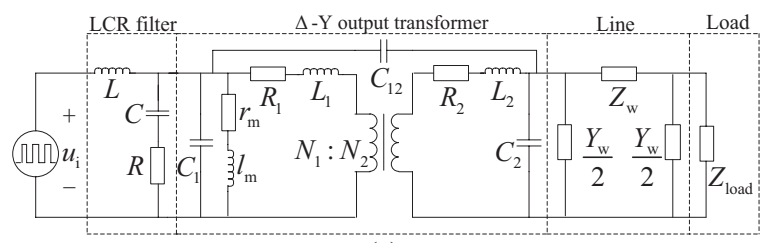

(a)

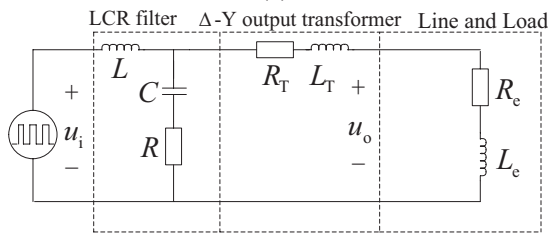

(b)

Fig. 6. Models of LCR-T filter: (a) equivalent model, and (b) simplified model.

In the industrial field, the air usually contains much dust. By the layered design, most of the dust can drain out of the power unit with the air. At the same time, the power devices and drivers are placed in reverse on the high-density fins radiator to protect from the dust.

In power unit topology, the uncontrollable rectifiers are used on the left side to reduce control complexity and cost. On the right side, the H-bridge cascaded inverter is used to output more levels and higher voltage to reduce output harmonic voltage components. Moreover, each unit has a bypass switch. Once the power unit fails, the redundancy can be achieved by using the bypass switch.

\section{LCR-T Filter}

The LCR-T filter consists of LCR and $\Delta$-Y output transformer as shown in Fig. 5. The signal cables from the Potential Transformers (PT) are putting into cabinet wire slot to avoid electromagnetic interference from converter. The discharge coils are used to fast release the energy of capacitors in case of the RESPS stop working.

Fig. 6 shows the models of the LCR-T filter. In Fig.6(a), the relatively accurate model is provided to describe the equivalent model. And, the simplified model is given in Fig.6 (b) to simplify the analysis and industrial design. Based on the simplified model, system transfer function can be expressed as:

$$
\left.G(s)\right|_{\frac{u_{\mathrm{o}}}{u_{\mathrm{i}}}}=\frac{R C L_{\mathrm{e}} s^{2}+\left(L_{\mathrm{e}}+R C R_{\mathrm{e}}\right) s+R_{\mathrm{e}}}{A_{3} s^{3}+A_{2} s^{2}+A_{1} s+R_{\mathrm{e}}+R_{\mathrm{T}}}
$$




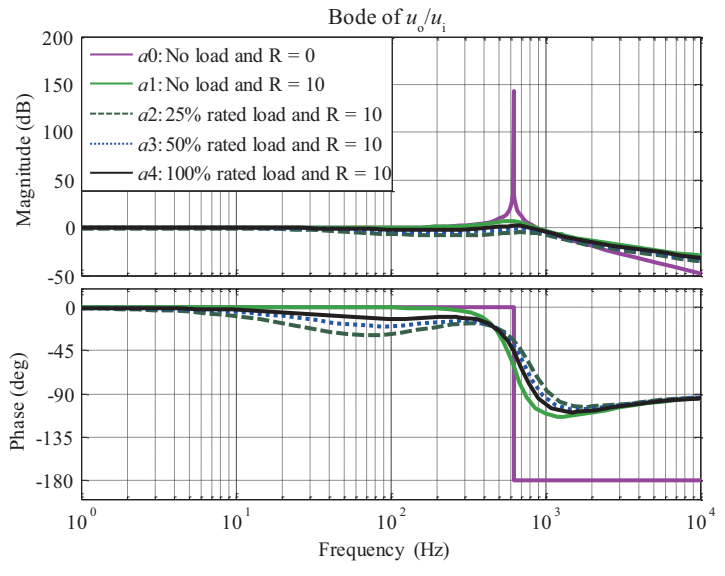

Fig. 7. Bode chart of magnitude-frequency characteristics of LCR-T filter under different rated load and $R$ value.

where

$$
\left\{\begin{array}{l}
A_{1}=L+L_{\mathrm{e}}+L_{\mathrm{T}}+R C R_{\mathrm{e}}+R C R_{\mathrm{T}} \\
A_{2}=R C L+L C R_{\mathrm{e}}+R C L_{\mathrm{e}}+L C R_{\mathrm{T}}+R C L_{\mathrm{T}} \\
A_{3}=L C L_{\mathrm{e}}+L C L_{\mathrm{T}}
\end{array}\right.
$$

In Fig. 6, (1) and (2), the $R_{\mathrm{T}}$ and $L_{\mathrm{T}}$ are transformer equivalent impedance to the primary side; $R_{\mathrm{e}}$ and $L_{\mathrm{e}}$ are the equivalent impedance of the line and load referred to the primary side. $u_{\mathrm{i}}$ is the input voltage for LCR-T filter, and $u_{\mathrm{o}}$ is the output voltage for LCR-T filter referred to the primary side.

Based on (1), Fig. 7 shows the magnitude and phase with varying the frequency under different rated loads. The objectives of the LCR-T filter include two parts: 1) In high frequency band ( $>2 \mathrm{kHz}$ ), the filter exhibits high damping, so the high frequency harmonics of the H-bridge cascaded inverter will not enter into the EDSS. 2) The orders of harmonic current of EDSS mainly include few lower frequency harmonics ( < $1 \mathrm{kHz}$ ), and the damping of the filter is small, so the harmonic current can flow through the filter smoothly.

As can be seen from Fig. 7, the resistor $R$ is necessary. Otherwise, the resonance problem (see curve a0) is liable to occur. And based on the design of LCR-T filter, the RESPS can provide the smooth voltage waveforms to the distribution loads.

\section{E. Prototype Assembling and Key Parameters of RESPS}

In this part, a $27.5 / 10 \mathrm{kV}, 1000 \mathrm{kVA}$ RESPS industrial prototype is constructed into two containers as shown in Fig. 8. And, the key parameters of the RESPS are given in Table I. During the assembly process, the insulation and the grounding protect are well considered. And the IGBT used for this application is FF600R17ME4 produced by Infineon.

\section{Control System of the RESPS}

In this section, the control system of the RESPS is discussed in two parts, namely: A. overcurrent driver fault analysis, B. control strategy.

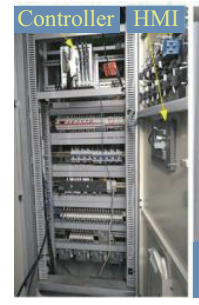

(a)

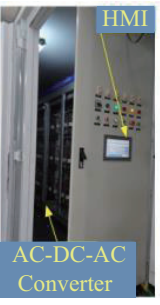

(b)

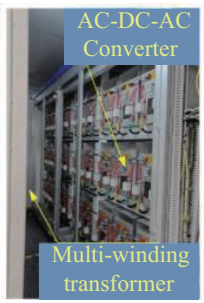

(c)

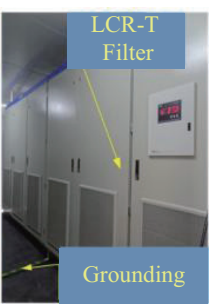

(d)
Fig. 8. Prototype assembling of the RESPS: (a) Controller and HMI in container NO.1, (b) AC-DC-AC converter in container NO.1, (c) Multiwinding transformer in container NO.1, (d) LCR-T filter in Container NO.2.

TABLE I

Key Parameters of RESPS in Industrial ApPlication

\begin{tabular}{ll}
\hline \hline Element & Value \\
\hline RESPS Rated Capacity & $1000 \mathrm{kVA}$ \\
Multi-winding Transformer Turn Ratio & $27.5 / 0.625 \mathrm{kV}$ \\
Multi-winding Transformer Short-circuit Voltage & $8 \%$ \\
Auxiliary Winding Output Voltage & $240 \mathrm{~V}$ \\
Impedance Deviation Each Secondary Winding & $<5 \%$ \\
IGBT & $1700 \mathrm{~V} / 600 \mathrm{~A}$ \\
Inductor & $4.8 \mathrm{mH} / 156 \mathrm{~A}$ \\
Capacitor & $13.6 \mu \mathrm{F}$ \\
Resistor & $10 \Omega$ \\
Output transformer Turn Ratio & $3.7 / 10.5 \mathrm{kV}$ \\
Output transformer Short-circuit Voltage & $8 \%$ \\
Output transformer Connection Symbol & $\Delta / \mathrm{Y}$ \\
\hline \hline
\end{tabular}

\section{A. Overcurrent Driver Fault Analysis}

As the most important protection of IGBTs, short-circuit protection is often used as the last part of the IGBT protection. However, when the loads are the network, the short-circuit protection will occur even if there is no real short-circuit fault. And this is very different with powering a single dedicated load. For example, when multiple feeder transformers engaged in network, the transformer magnetizing inrush current flows through the RESPS and cause the extreme fluctuations on the output voltage. And RESPS will regulate the voltage to the reference very quickly. According to (3), once the value of voltage adjustment is too large, the capacitor current will be recognized as a short-circuit fault by the driver. This will become an inescapable fate problem for high-voltage SPS or energy routers in practical applications.

The circuit of inverter and $L C R$ can be equivalent to the Fig. 9(a), where $v_{\mathrm{L}}, v_{\mathrm{s}}, v_{\mathrm{i}}$ are inductor voltage, output voltage of the $\mathrm{H}$-bridge cascaded inverter and LCR branch voltage, $i_{\mathrm{i}}, i_{\mathrm{T}}$ and $i_{\mathrm{c}}$ are the input, output current of the LCR and capacitor current.

The overcurrent driver fault process can be summarized as follows: When the magnetizing inrush current generated, $i_{\mathrm{T}}$ and $i_{\mathrm{i}}$ increase, so $v_{\mathrm{L}}$ will become larger. This will result in a decrease of $v_{\mathrm{i}}$. So the controller will regulate $v_{\mathrm{i}}$ to the reference value. As shown in Fig. 9(b), when the adjustment value $\Delta v_{i_{2}}$ is too large, the current $i_{\mathrm{c}}$ will sharply increase in a very short 


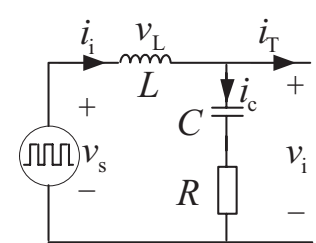

(a)

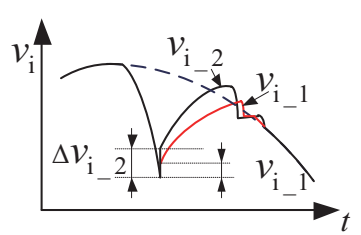

(b)
Fig. 9. The reason of overcurrent driver fault: (a) Equivalent circuit, and (b) Voltage regulation process.

time according to (3). At this time, the driver would recognize the current as a short-circuit fault.

$$
i_{\mathrm{c}}=C \frac{\mathrm{d} v_{\mathrm{i}}}{\mathrm{d} t}
$$

The voltage on resistor $R$ is ignored in (3) since the fundamental impedance of the capacitor is much greater than the impedance of the resistor. On the other hand, on the basis of the inrush current, the increase of $i_{\mathrm{c}}$ further increases $i_{\mathrm{i}}$. This creates a vicious circle of overcurrent driver fault.

Main purpose of the control strategy is to output high quality voltage and reduce overcurrent driver fault. Therefore, according to the above analysis, the solution can be obtained by reducing the $\Delta v_{i_{2}}$. For example, regulate voltage from $\Delta v_{i_{2}}$ to $\Delta v_{\mathrm{i}_{1} 1}$, make the curve $v_{\mathrm{i}_{2}}$ closing to curve $v_{\mathrm{i}_{1} 1}$.

\section{B. Control Strategy}

As illustrated in Fig. 10, the proposed control strategy can be considered into four parts, namely: main control loop (including piecewise linear PI control), auxiliary control loop, and normalization, PWM control.

\section{1) Main Control Loop}

The main control loop is to control the voltage $v_{\mathrm{i}}$ of the $R C$ branch to the reference voltage $u_{\text {ref }}{ }^{*}$ by a piecewise linear PI control. Most important, the piecewise linear PI control is to ensure sufficient PI gain under normal conditions and reduce the gain to slow down the adjustment speed in extreme cases to avoid overcurrent driver fault.

To solve the problem based on the previous analysis (see part B), the proposed piecewise linear PI control strategy can be indicated as follow:

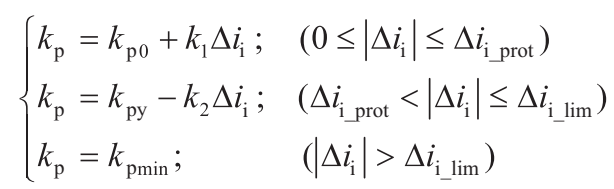

Where $k_{\mathrm{p} 0}$ and $k_{\mathrm{py}}$ are the intercept of the linear function; $k_{1}$ and $k_{2}$ are the piecewise linear slopes; $\Delta i_{1}$ represents the current rate of the change. $\Delta i_{\mathrm{i}}$ prot and $\Delta i_{\mathrm{i}}$ lim are the current demarcation point corresponding to $k_{\mathrm{p}}$ demarcation point.

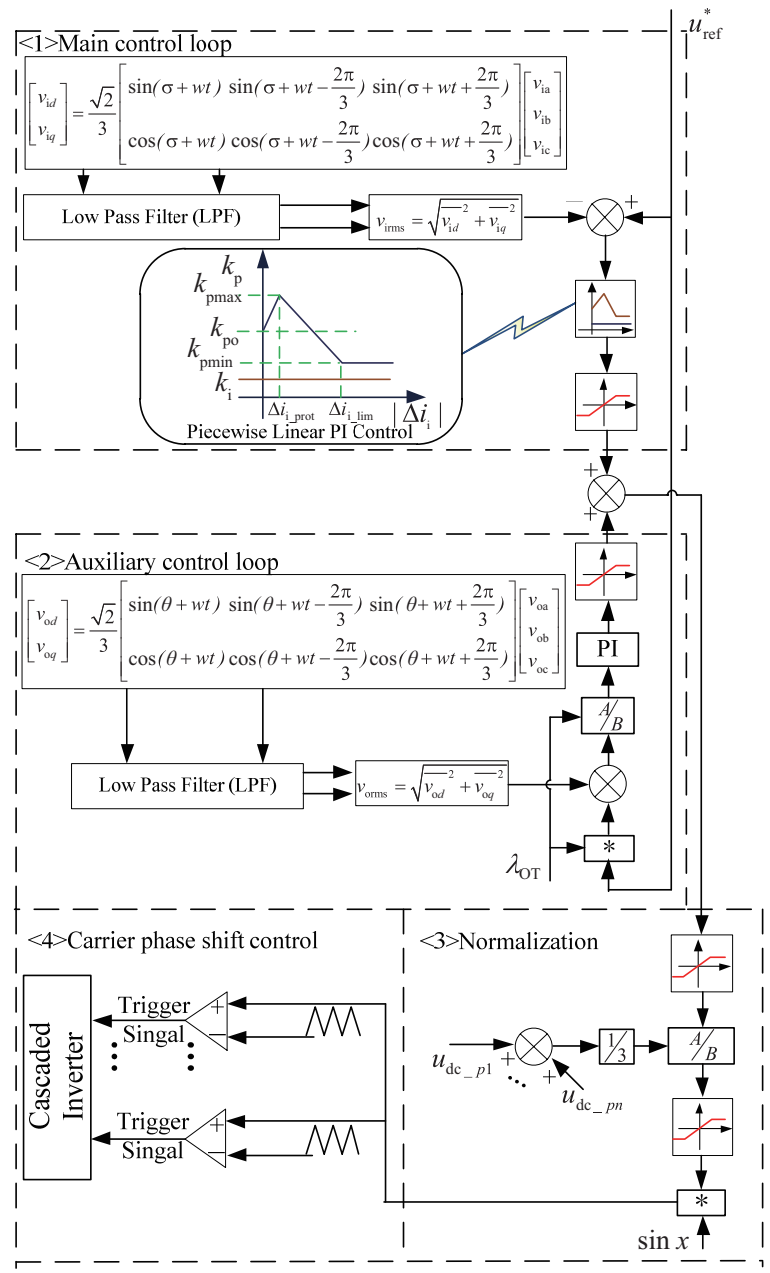

Fig. 10. The control strategy of the RESPS.

According to the proposed controller, the process of decreasing overcurrent driver fault is addressed:

- When $\Delta i_{\mathrm{i}}$ normally increased, $k_{\mathrm{p}}$ gradually increased in order to ensure the sufficient control gain and tracking speed.

-When $\Delta i_{\mathrm{i}}$ increased to $\Delta i_{\mathrm{i} \text { prot }}$ (while inrush current), overextended $\Delta v_{\mathrm{i}}$ will increase $\Delta i_{\mathrm{i}}$ (see part B), so the control gain does not continue increasing, and $k_{\mathrm{p}}$ reaches the maximum $k_{\text {pmax }}$ at this time.

- When $\Delta i_{\mathrm{i}}$ exceeds $\Delta i_{\mathrm{i} \text { prot }}$, in order to reduce $\Delta v_{\mathrm{i}}$ as quickly as possible, the gain $k_{\mathrm{p}}$ does not increase, but decreases rapidly.

- In order to ensure the integrity of the industrial control system, when $\Delta i_{\mathrm{i}}$ reaches the maximum $\Delta i_{\mathrm{i} \_ \text {lim, }}$, the control gain $k_{\mathrm{p}}$ reduced to the minimum $k_{\text {pmin. }}$.

Generally, $\Delta i_{\mathrm{i}}$ prot and $\Delta i_{\mathrm{i}}$ lim can take $10 \%-30 \%, 40 \%-50 \%$ of the IGBT repetitive peak collector current respectively.

Since the design of PI controller has been widely discussed [35]-[38], this part only discusses the maximum boundary of $k_{\mathrm{p}}$ for this specific application.

The PI control can work in normal situation which can be expressed as: 


$$
\left\{\begin{array}{l}
e(k)=u_{\mathrm{ref}}^{*}-v_{\mathrm{i}}(k) \\
k_{\mathrm{p}} e(k)+k_{\mathrm{i}} \sum_{i=1}^{k} e(i)=v_{\mathrm{i}}
\end{array}\right.
$$

Where $k$ is the sample time, $k_{\mathrm{P}}$ and $k_{\mathrm{i}}$ are the proportional gain and integral gain.

Again, according to the equivalent circuit in Fig. 9(a), the voltage equation can be got:

$$
v_{\mathrm{s}}-v_{\mathrm{L}}=v_{\mathrm{i}}
$$

At the same time, the $v_{\mathrm{i}}$ also can be expressed:

$$
v_{\mathrm{i}}=L \frac{\mathrm{d} i_{\mathrm{i}}}{\mathrm{d} t}
$$

Importantly, (6) and (7) are taken into (5), the expression can be got:

$$
k_{\mathrm{p}}=\frac{v_{\mathrm{s}}-L \mathrm{~d} i_{\mathrm{i}} / \mathrm{d} t-k_{\mathrm{i}} \sum_{i=1}^{k} e(i)}{e(k)}
$$

In the actual control system, the tracking speed will be determined primarily by $k_{\mathrm{p}}$. Therefore, it can be assumed that $k_{\mathrm{i}}$ $=0$, then the maximum $k_{\text {pmax }}$ gain can be expressed as:

$$
k_{\mathrm{p} \max } \leq \frac{v_{\mathrm{s}}-L \Delta i_{\mathrm{i} \text { prot }} / \Delta t}{v_{\text {dev }}}
$$

where the maximum value of $v_{\mathrm{s}}$ is the output voltage peak of the cascaded inverter, and $\Delta t$ is the time of the control cycle. And $e(k)$ is the maximum voltage deviation $v_{\text {dev }}$ allowed by the control, and generally is $3 \%-7 \%$ rated voltage.

Based on above control, the entire process of piecewise linear PI control can be determined just like in Fig. 9(b).

\section{2) Auxiliary Control Loop}

The auxiliary control loop is very important to improve the output voltage accuracy. In particular, the auxiliary control loop needs special handling:

- Auxiliary control loop can eliminate the voltage deviation of output voltage through PI controller. Because when the current generated, the transformer's impedance will produce a corresponding voltage drop.

- The calculated value of the auxiliary control loop must be scaled and superimposed on the main control loop for unified calculation.

- Before the superposition, the calculation result of the auxiliary control loop must be limited to the allowable range.

And generally, the allowable range is limited in 3\%-7\% of the rated voltage.

\section{3) Normalization}

In this part, the control variable is normalized by the DC

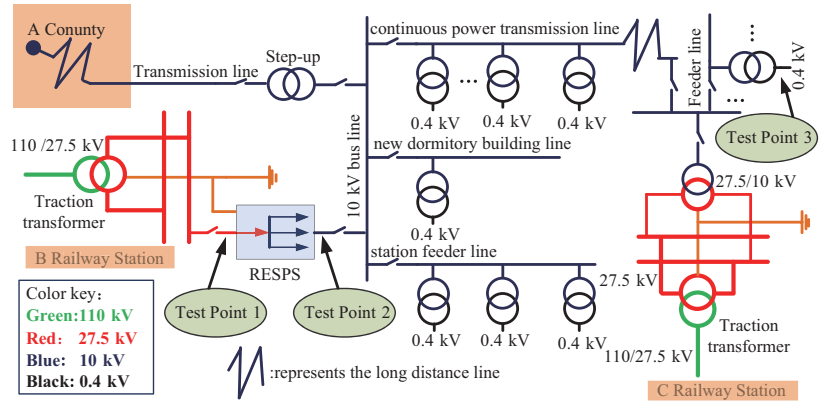

Fig. 11. Circuit network on field in Turpan-Korla railway.

voltage. And, the purpose of normalization is to improve the adjustment accuracy of the RESPS, especially when the input side voltage fluctuates. And also, it is convenient for PWM modulation.

\section{4) PWM Control}

After normalization, the controller performs PWM control by carrier phase shifting (CPS).

Whereas, $v_{\mathrm{ia}}, v_{\mathrm{ib}}, v_{\mathrm{ic}}$ and $v_{\mathrm{oa}}, v_{\mathrm{ob}}, v_{\mathrm{oc}}$ represent $R C$ voltage and output voltage, respectively. $u_{\mathrm{dc} p n}(p=A / B / C, n=1 \cdots 9)$ are DC voltage of power unit. $i_{\mathrm{ia}}, i_{\mathrm{ib}}, i_{\mathrm{ic}}$ are the H-bridge cascaded inverter output current. $u_{\text {ref }}^{*}$ is the reference on $R C$ branch. $\lambda_{\text {от }}$ is output transformer turn ratio. $\sin x(x=A / B / C)$ represents the unit sine function in phase with the voltage.

\section{EXPERIMENTAL AND SimUlation}

In this section, the experimental results are provided to verify the feasibility and validity of RESPS. The circuit network on field and the industrial platform are provided in Fig. 11 for 27.5/10 kV, $1000 \mathrm{kVA}$ RESPS in Turpan-Korla railway. The purpose of the RESPS is to keep the voltage quality of test points $2(10 \mathrm{kV})$ and test point $3(0.4 \mathrm{kV})$ to be satisfactory according to the Chinese standards [39], [40].

The tests of RESPS include: A. inrush current shock test and simulation, B. dynamic load shock test, C. input and output voltage quality test, D. single phase grounding fault test and $\mathrm{E}$. low voltage side voltage quality test.

\section{A. Inrush Current Shock Simulation and Test}

This part aims to verify that the piecewise linear PI control strategy of RESPS can reduce overcurrent driver fault problem during the excitation inrush current.

\section{1) Inrush Current Shock Experiment}

The inrush current in Fig. 12 is caused by a 10/0.4 kV 500 $\mathrm{kVA}$ transformer engaged, and the maximum instantaneous load current of the RESPS is as high as $130 \mathrm{~A}$ peak (369 A in inverter) in phase C. At the beginning of large inrush current, the controller reduces the $k_{\mathrm{p}}$ value to slow down the adjustment speed of the voltage regulation. After the inrush current reduced, the $k_{\mathrm{p}}$ value increased in order to ensure the tracking speed of the output. The experimental results in Fig. 12 are 


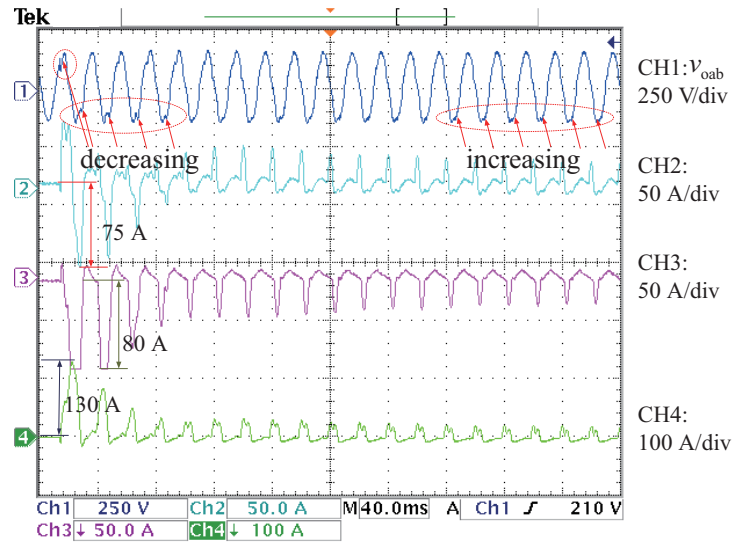

Fig. 12. The waveforms of the RESPS output voltage and output current of phase A, B and C due to transformer excitation inrush current.

consistent with the previous control strategy analysis. And, there is no significant overshoot and over current driver fault problem. And the parameters of piecewise linear PI controller in main control loop are:

$$
\left\{\begin{array}{l}
k_{\mathrm{p}}=2.2+0.163022 \Delta i_{\mathrm{i}} ; \quad\left(0 \leq\left|\Delta i_{\mathrm{i}}\right| \leq 112.5\right) \\
k_{\mathrm{p}}=31.664-0.09888 \Delta i_{\mathrm{i}} ; \quad\left(112.5<\left|\Delta i_{\mathrm{i}}\right| \leq 300\right) \\
k_{\mathrm{p}}=2 ; \quad\left(\left|\Delta i_{\mathrm{i}}\right|>300\right)
\end{array},\right.
$$

And the $K_{\mathrm{i}}$ is 0.02 . The parameters of PI controller in Auxiliary control loop are: $K_{\mathrm{p}}=1.2$ and $K_{\mathrm{i}}=0.02$.

\section{2) Excitation Inrush Current Shock Simulation}

In order to fully prove the benefits of piecewise linear PI while inrush current occurring, the simulation model is built by using PSIM software.

As shown in Fig. 13, an inrush current generated at the time of 0.298 s. The subscript " 11 " is the simulation result of the piecewise linear PI controller, and the subscript " 2 " is the simulation result of the constant PI controller. When the inrush current occurs, $k_{\mathrm{p}}$ begins to decrease. The LCR branch voltage $v_{\mathrm{i}}$ is significantly optimized $\left(\Delta v_{\mathrm{i}_{1} 1}<\Delta v_{\mathrm{i}_{2} 2}\right)$ by piecewise linear PI. Moreover, the capacitor current is also reduced $\left(\Delta i_{\mathrm{c} \_1}\right.$ $\left.<\Delta i_{\text {c } 2}\right)$. After the inrush current is stabilized, the piecewise linear PI controller increases $k_{\mathrm{p}}$. And the increased $k_{\mathrm{p}}$ improves the tracking speed to achieve a fast output voltage dynamic recovery speed as indicated in Fig. 13.

\section{B. Dynamic Load Test}

Fig. 14 shows the dynamic changing of load apparent power, active power, load current and output voltage of the RESPS. In Fig. 14, through observations of up to 60 minutes, it can be seen that the output voltage can be kept within $10.25 \pm 0.06 \mathrm{kV}$ when the load apparent power, active power, load current are varying from $80 \mathrm{kVA}$ to $160 \mathrm{kVA}, 70 \mathrm{~kW}$ to $130 \mathrm{~kW}$ and $4.5 \mathrm{~A}$ to $9 \mathrm{~A}$.

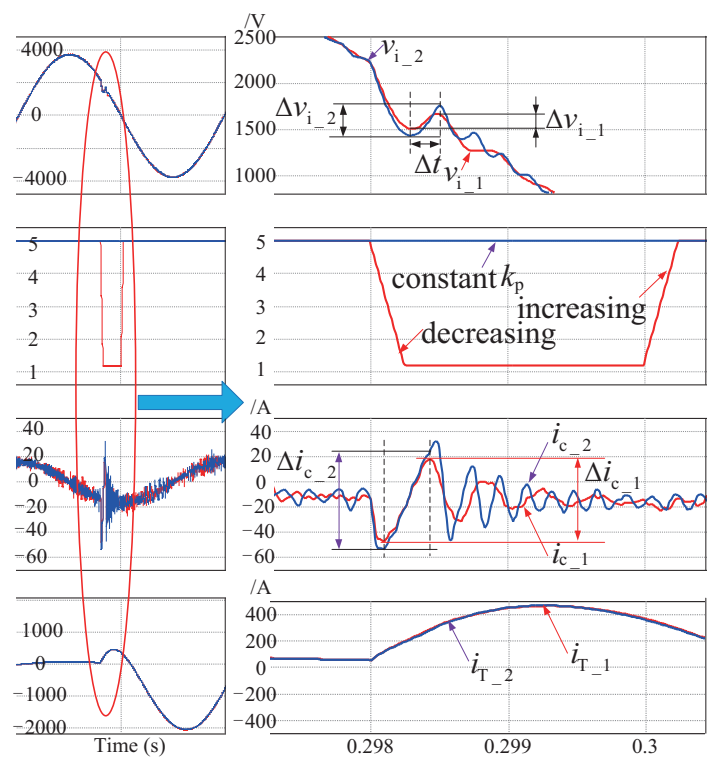

Fig. 13. Simulation of $k_{\mathrm{p}}$ change process during inrush current.

\section{Input Voltage and Output Voltage Quality Test}

This part aims to prove the practical functions of the RESPS. Fig. 15 and 16 show the input traction voltage (Test Point 1 ) and output voltage (Test Point 2 ) of the RESPS.

As shown in Fig. 15(a), when a regular train passes through the traction arm, the input voltage waveform of the RESPS is distorted. And, the input voltage fluctuation is from $26.85 \mathrm{kV}$ to $28.74 \mathrm{kV}$ as reflected the measurement by PT $(85.25 \mathrm{~V}$ to $91.25 \mathrm{~V}$ in Fig. 15(b)). Moreover, the input voltage total harmonic distortion $\left(T H D_{\mathrm{u}}\right)$ is about $3.6 \%$ as in Fig. $15(\mathrm{c})$. In fact, the voltage quality is far worse than this.

In contrast, as in Fig. 16(a), the output voltage waveform of the RESPS is very smooth. Specially, in a 96-hour observation, the output voltage of the RESPS is always maintained within $10.25 \mathrm{kV} \pm 0.08 \mathrm{kV}$ as in Fig. 16(b). Moreover, the output voltage $T H D_{\mathrm{u}}$ can be kept to less than $1 \%$ as in Fig. 16(c).

\section{Single Phase Grounding Fault Test}

In order to meet the operation and maintenance requirements of EDSS, the RESPS should work continuously when there is a single phase grounding fault on the output side. As shown in Fig. 17, during normal operation, the $\mathrm{A} / \mathrm{B} / \mathrm{C}$ phase-to-ground voltage is $5.92 \mathrm{kV}$. And grounding fault in phase $\mathrm{C}$ suddenly occurs, the $\mathrm{C}$ phase-to-ground voltage drops to zero sharply. At the same time, A and B phase-to-ground voltage rise to 10.25 $\mathrm{kV}$. So, the phase to phase voltage can remain the same.

\section{E. Comparisons of Voltage Quality Test on Low Voltage Side Between Traditional Transformer and the Proposed RESPS}

The measurement results of the distribution side voltage by using traditional transformer $(27.5 / 10 \mathrm{kV})$ and the proposed RESPS are provided in Fig. 18 and 19 and Table II.

Traditionally, the railway station supplies power by a 


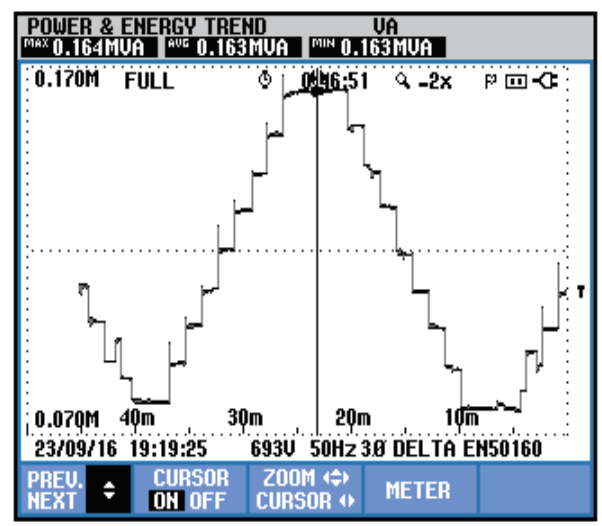

(a)

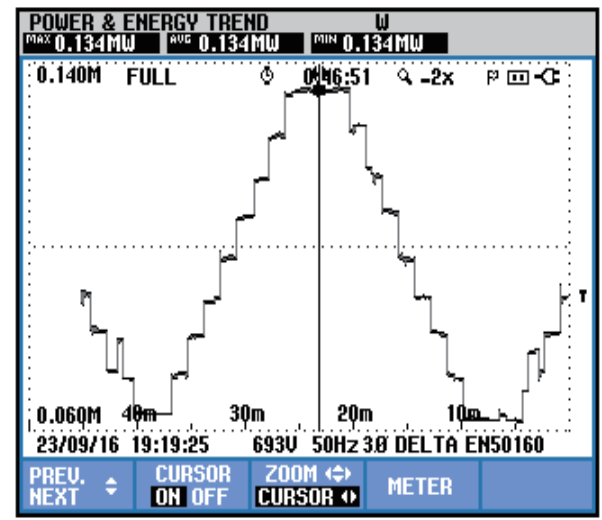

(b)

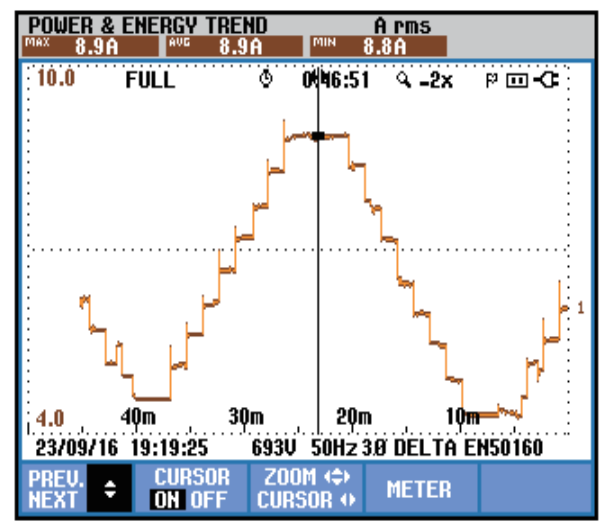

(c)

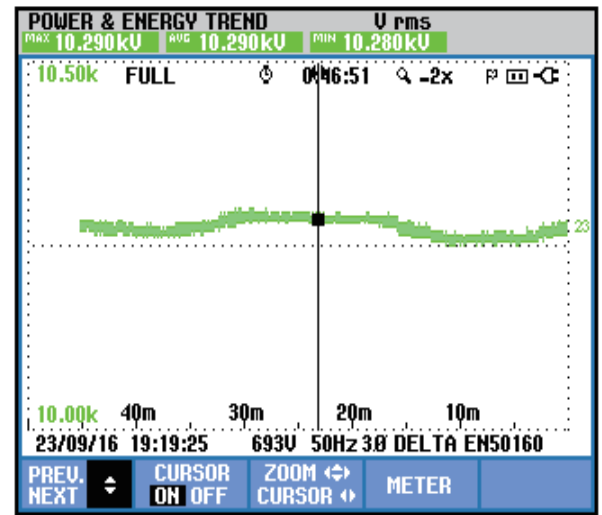

(d)

Fig. 14. Dynamic load test: (a) load apparent power, (b) load active power, (c) load current, and (d) output voltage of the RESPS.

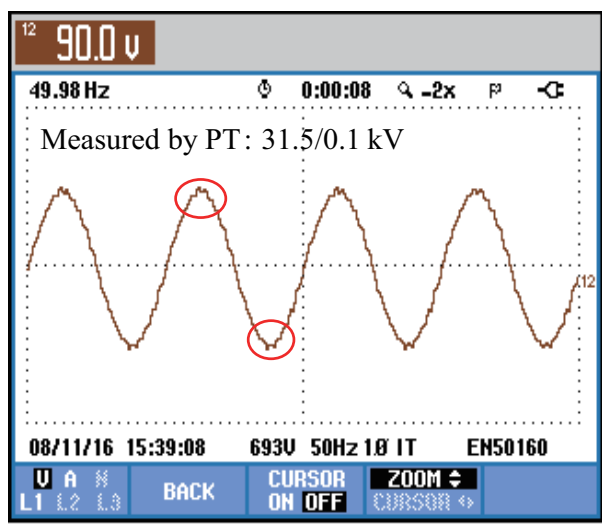

(a)

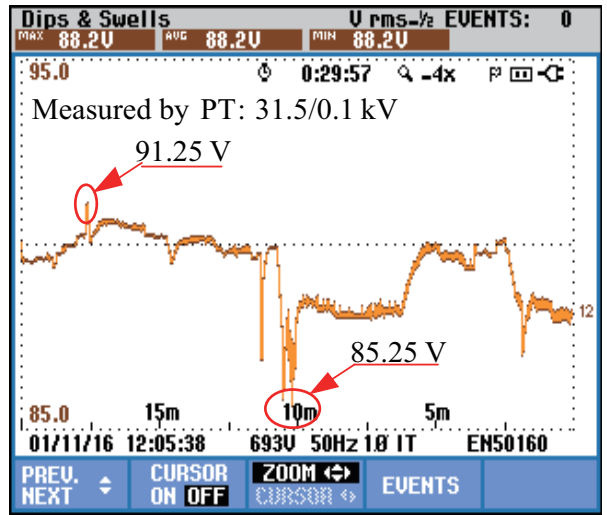

(b)

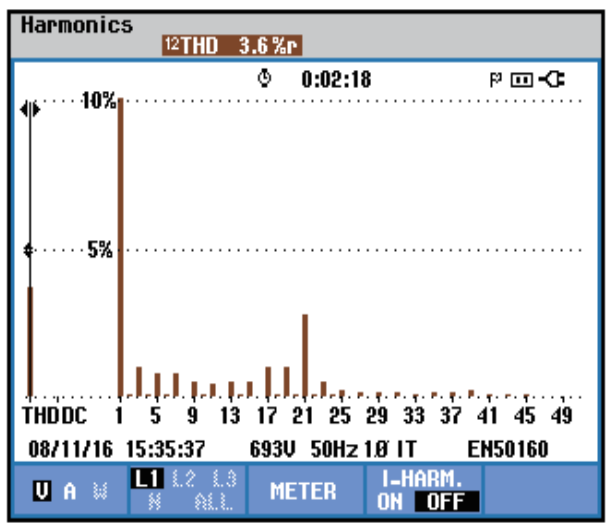

(c)

Fig. 15. The input voltage of RESPS (Test Point 1): (a) voltage waveform, (b) voltage digs \& swell, and (c) voltage harmonics spectrum.

27.5/10 kV transformer to the station feeder line. Due to the nonlinearity and impact of the locomotive, the low-voltage equipment can be easily abnormally operated in the station. Based on Fig. 18(c) $\left(T H D_{\mathrm{u}}>5 \%\right)$ and Fig. 18(d) $\left(U F_{\mathrm{u}}>5 \%\right)$, which cannot satisfy the Chinese standards [39] and [40], respectively. Moreover, the fluctuation range of the low voltage side is from $215 \mathrm{~V}$ to $235 \mathrm{~V}$, as shown in Fig. 18(b). With the proposed RESPS as shown in Fig. 19 and Table II, the voltage waveform is smooth with much less harmonic components, as shown in Fig. 19(a). Through the observation data for $30 \mathrm{~min}$, the distribution side phase voltage fluctuation is about $226 \mathrm{~V}$ $\pm 1 \mathrm{~V}$, as shown in Fig. 19(b). The $T H D_{\mathrm{u}}$ and $U F_{\mathrm{u}}$ are equal to 


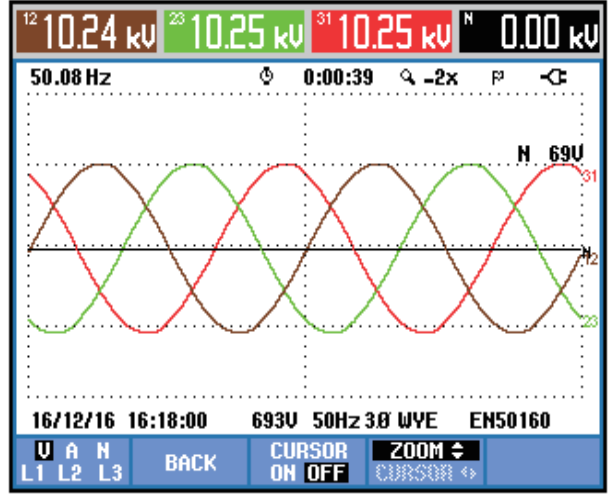

(a)

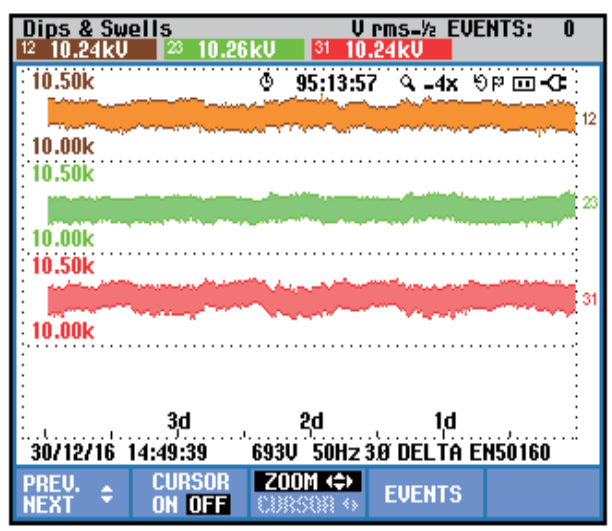

(b)

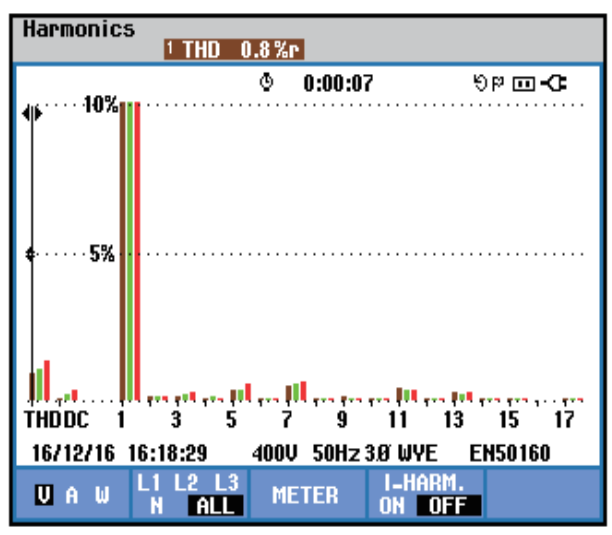

(c)

Fig. 16. The output voltage of RESPS (Test Point 2): (a) voltage waveform, (b) voltage digs \& swell, and (c) voltage harmonics spectrum.

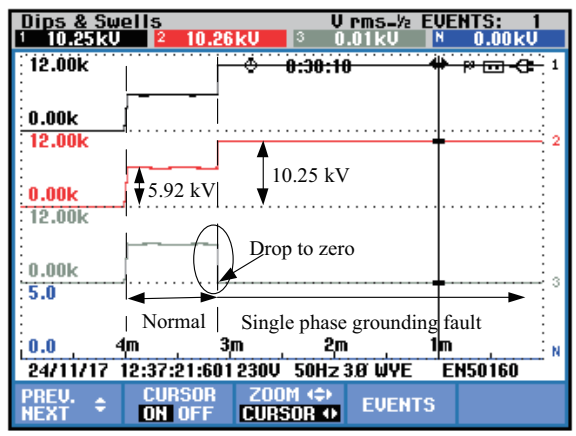

Fig.17. Single phase grounding fault occurred during operation.

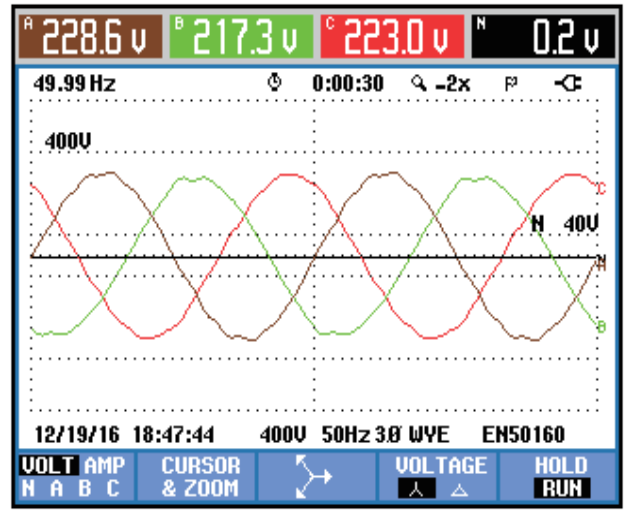

(a)

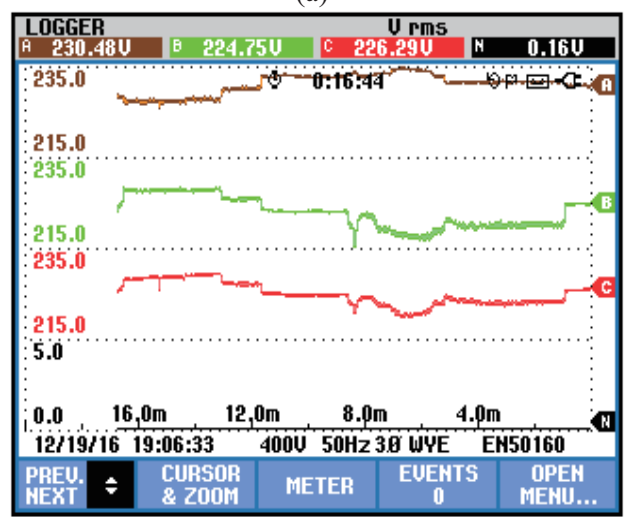

(b)

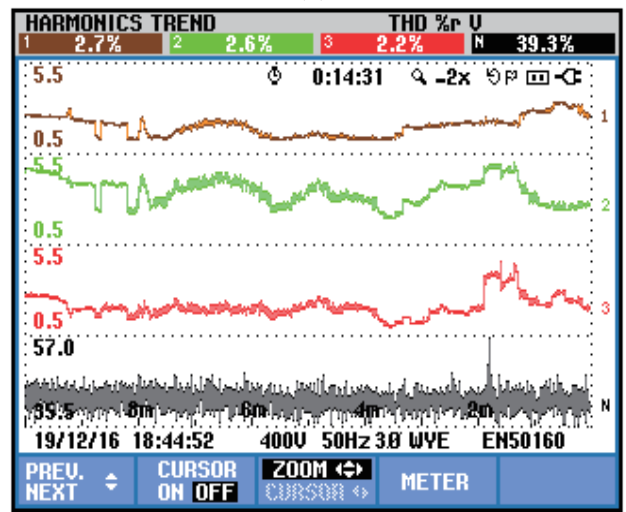

(c)

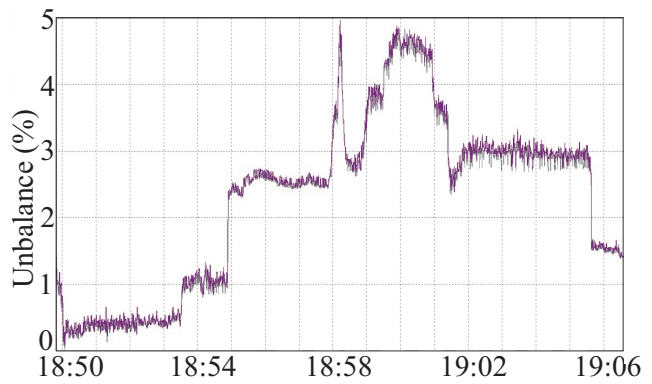

(d)

Fig. 18. The distribution side voltage by using traditional transformer (Test Point 3): (a) phase voltage waveform, (b) voltage magnitudes, (c) voltage harmonics trend, and (d) voltage unbalance trend.

$1.2 \%$ (Fig. 19(c)) and $0.08 \%$ (in Fig. 19(d)) which can well satisfy the Chinese standards [39] and [40]. 


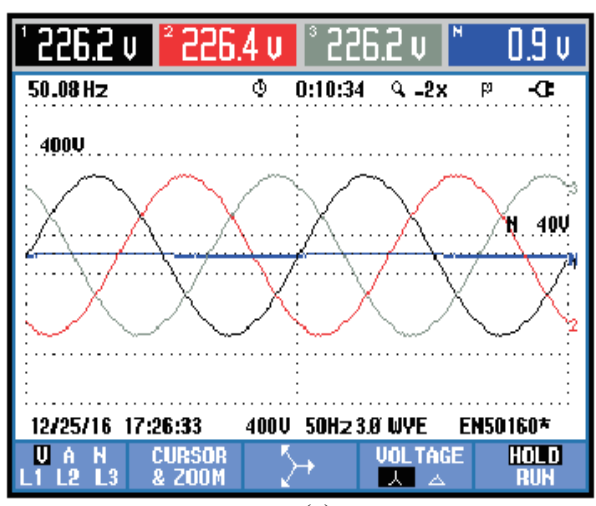

(a)

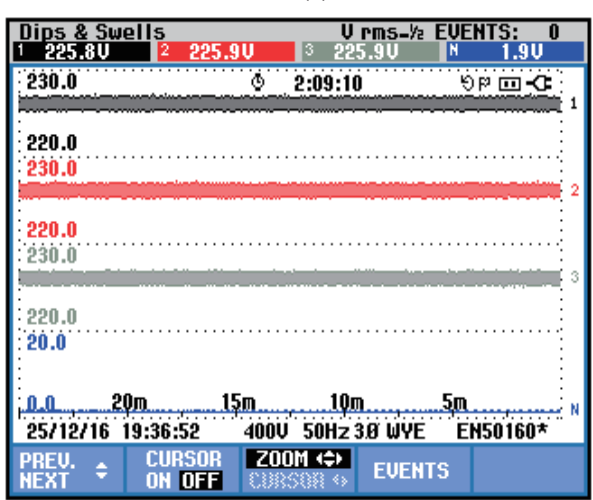

(b)

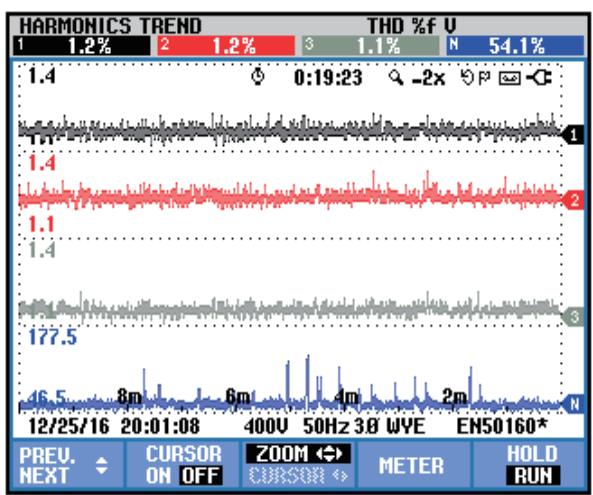

(c)

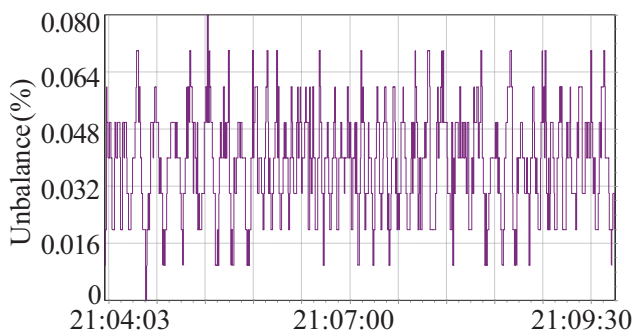

(d)

Fig. 19. The distribution side voltage by using the proposed RESPS (Test Point 3): (a) phase voltage waveform, (b) voltage magnitudes, (c) voltage harmonics trend, and (d) voltage unbalance trend.

\section{CONCLUSIONS}

In this paper, a dedicated $27.5 / 10 \mathrm{kV}, 1000 \mathrm{kVA}$ Railway Electric Special Power Supply (RESPS) is proposed and cons-
TABLE II

Comparison of Distribution Side Voltage by Using the Traditional Transformer and the Proposed RESPS

\begin{tabular}{lcc}
\hline \hline & Traditional transformer & Proposed RESPS \\
\hline Voltage fluctuation $(\mathrm{V})$ & $215 \mathrm{~V}-235 \mathrm{~V}$ & $225 \mathrm{~V} \pm 1 \mathrm{~V}$ \\
$T H D_{\mathrm{u}}(\%)$ & $5.5 \%$ & $<1.2 \%$ \\
$U F_{\mathrm{u}}(\%)$ & (Not satisfy standard [39]) & \\
& $5 \%$ & $<0.08 \%$ \\
\hline
\end{tabular}

tructed for railway substation. The topology, control scheme, industrial design methods and a series of application experiments of the RESPS are discussed in the paper. The simulation and experimental results have proved that the proposed scheme meets the established design principle and application requirements.

Since 2016, the RESPS has been applied in Turpan-Korla railway, China. Here, the paper summarizes some thoughts based on the research process and the problems in practical applications. Perhaps these conclusions are not mature, but author hope that these summaries can be helpful to the further research.

1) A series of application results prove that RESPS is feasible. Moreover, the proposed RESPS connects the RTPS and EDSS through power electronic conversion, which is equivalent to realizing the basic functions of network backbone energy router.

2) From the perspective of system operation and maintenance, RESPS will change the independent operation and maintenance of traditional traction supply substations and electric distribution supply substations.

3) A device similar to the RESPS will further increase the flexibility of the railway electric distribution supply system. At the same time, these devices will build a railway-specific micro grid with interface of power electronics conversion, and further increase the flexibility of the railway electric distribution supply system (railway-specific micro grid).

4) The most important, author believes that, when supplying power to the load network, the control method proposed helps to improve the continuous operation capability of the system once inrush current occured. Especially when the off-grid high-voltage inverter power supply and energy router are applied in the regional network, it has important practical significance.

Based on the field experimental results, the proposed RESPS can provide stable and high quality output voltage in the tests. Hopefully, more research on RESPS can be applied to railways to reduce costs and increase flexibility, especially to solve the problems of insufficient power supply and a waste of resource.

\section{REFERENCES}

[1] X. L. Jiang, Z. J. Zhang, J. H. Yuan, Q. Hu, and L. Y. Luo, "Study on AC pollution flashover performance of composite insulators at high altitude sites of 2800-4500 m," in IEEE Transactions on Dielectrics and Electrical Insulation, vol. 16, no. 1, pp. 123-132, Feb. 2009. 
[2] J. P. Xiao and L. B. Liu, "Permafrost subgrade condition assessment using extrapolation by deterministic deconvolution on multi frequency GPR data acquired along the Qinghai-Tibet railway," IEEE Journal of Selected Topics in Applied Earth Observations and Remote Sensing, vol. 9, no. 1, pp. 83-90, Jan. 2016.

[3] Y. M. Cai, Z. Y. He, and Q. Q. Qian, “Autonomous decentralized architecture based protection and supervisory control system of railway automatic blocking and continuous transmission line," in 2005 IEEE/ PES Transmission \& Distribution Conference \& Exposition: Asia and Pacific, Dalian, China, 2005, pp. 1-5.

[4] H. T. Hu, Z. Y. He, X. Li, K. Wang, and S. B. Gao, "Power-quality impact assessment for high-speed railway associated with high-speed trains using train timetable-Part II: Verifications, estimations and applications," in IEEE Transactions on Power Delivery, vol. 31, no. 4, pp. 1482-1492, Aug. 2016.

[5] S. M. M. Gazafrudi, A. T. Langerudy, E. F. Fuchs, and K. Al-Haddad, "Power quality issues in railway electrification: A comprehensive perspective," in IEEE Transactions on Industrial Electronics, vol. 62, no. 5, pp. 3081-3090, May 2015.

[6] Q. Y. Sun, S. Chen, L. Chen, and D. Z. Ma, "Quasi-Z-source networkbased hybrid power supply system for aluminum electrolysis industry," in IEEE Transactions on Industrial Informatics, vol. 13, no. 3, pp. 1141-1151, Jun. 2017.

[7] D. Lutz, P. Renz, and P. R. Wicht, "An integrated 3-mW 120-230-V AC mains micro power supply," in IEEE Journal of Emerging and Selected Topics in Power Electronics, vol. 6, no. 2, pp. 581-591, Jun. 2018.

[8] C. S. Li and D. W. Xu, "Family of enhanced ZCS single-stage singlephase isolated AC-DC converter for high-power high-voltage DC supply," in IEEE Transactions on Industrial Electronics, vol. 64, no. 5, pp. 3629-3639, May 2017.

[9] H. J. Liu, K. J. Li, W. J. Lee, and H. Gao, "Development of frequency variable inverter based on SOPC and Nios II," in IEEE Transactions on Industry Applications, vol. 49, no. 5, pp. 2237-2243, Sept./Oct. 2013.

[10] A. Luo, H. G. Xiao, H. L. Ouyang, C. P. Wu, F. J. Ma, and Z. K. Shuai, "Development and application of the two-phase orthogonal power supply for electromagnetic stirring," in IEEE Transactions on Power Electronics, vol. 28, no. 7, pp. 3438-3446, Jul. 2013.

[11] J. H. Lu, M. Savaghebi, Y. J. Guan, S. Golestan, J. C. Vasquez, J. M. Guerrero, and A. Marzabal, "DC-link protection and control in modular uninterruptible power supply," in IEEE Transactions on Industrial Electronics, vol. 65, no. 5, pp. 3942-3953, May 2018.

[12] S. N. Vukosavić, L. S. Perić, and S. D. Sušić, "A novel power converter topology for electrostatic precipitators," in IEEE Transactions on Power Electronics, vol. 31, no. 1, pp. 152-164, Jan. 2016.

[13] C. B. Li, X. B. Liu, Y. J. Cao, P. Zhang, H. Q. Shi, L. Y. Ren, and Y. H. Kuang, "A time-scale adaptive dispatch method for renewable energy power supply systems on islands," in IEEE Transactions on Smart Grid, vol. 7, no. 2, pp. 1069-1078, Mar. 2016.

[14] D. Wang, J. Tian, C. X. Mao, J. M. Lu, and Y. P. Duan, “A 10-kV/400V 500kVA electronic power transformer," in IEEE Transactions on Industrial Electronics, vol. 63, no. 11, pp. 6653-6663, Nov. 2016.

[15] S. Bifaretti, P. Zanchetta, A. Watson, L. Tarisciotti, J. C. Clare, "Advanced power electronic conversion and control system for universal and flexible power management," in IEEE Transactions on Smart Grid, vol. 2, no. 2, pp. 231-243, Jun. 2011.

[16] R. Q. Machado, S. Buso, and J. A. Pomilio, "A line-interactive singlephase to three-phase converter system," in IEEE Transactions on Power Electronics, vol. 21, no. 6, pp. 1628-1636, Nov. 2006.

[17] Y. F. Zhou, W. X. Huang, and F. Hong, "Single-phase input variablespeed AC motor system based on an electrolytic capacitor-less singlestage Boost three-phase inverter," in IEEE Transactions on Power Electronics, vol. 31, no. 10, pp. 7043-7052, Oct. 2016.

[18] E. C. dos Santos, C. B. Jacobina, G. A. de A. Carlos, and I. S. de Freitas, "Component minimized AC-DC-AC single-phase to three-phase fourwire converters," in IEEE Transactions on Industrial Electronics, vol. 58, no. 10, pp. $4624-4635$, Oct. 2011.

[19] C. R. Baier, J. R. Espinoza, J. A. Muñoz, L. A. Morán, and P. E. Melín, "A high-performance multicell topology based on single-phase power cells for three-phase systems operating under unbalanced AC mains and asymmetrical loads," in IEEE Transactions on Industrial Electronics, vol. 57, no. 8, pp. 2730-2738, Aug. 2010.

[20] D. C. Lee and Y. S. Kim, "Control of single-phase-to-three-phase AC/DC/AC PWM converters for induction motor drives," in IEEE Transactions on Industrial Electronics, vol. 54, no. 2, pp. 797-804, Apr. 2007.

[21] N. Rocha, I. A. C. de Oliveira, E. C. de Menezes, C. Brandão Jacobina, and J. A. A. Dias, "Single-phase to three-phase converters with two parallel single-phase rectifiers and reduced switch count," in IEEE Transactions on Power Electronics, vol. 31, no. 5, pp. 3704-3716, May 2016.

[22] C. B. Jacobina, N. Rocha, N. S. de M. L. Marinus, and E. C. dos Santos, "Single-phase to three-phase DC-link converters with reduced controlled switch count," in IEEE Transactions on Industry Applications, vol. 50, no. 2, pp. 1150-1160, Mar./Apr. 2014.

[23] E. Cipriano, C. B. Jacobina, E. R. C. da Silva, and N. Rocha, "Singlephase to three-phase power converters: State of the art," in IEEE Transactions on Power Electronics, vol. 27, no. 5, pp. 2437-2452, May 2012.

[24] J. S. Lai, A. Maitra, A. Mansoor, and F. Goodman, "Multilevel intelligent universal transformer for medium voltage application," in Proceedings of Fourtieth IAS Annual Meeting. Conference Record of the 2005 Industry Applications Conference, Kowloon, Hong Kong, China, Oct. 2005, pp. 1893-1899.

[25] X. She, A. Q. Huang, and R. Burgos, "Review of solid-state transformer technologies and their application in power distribution systems," in IEEE Journal of Emerging and Selected Topics in Power Electronics, vol. 1, no. 3, pp. 186-198, Sept. 2013.

[26] S. Falcones, X. L. Mao, and R. Ayyanar, "Topology comparison for solid state transformer implementation," in Proceedings of IEEE Power Energy Society General Meeting, Providence, RI, USA, Jul. 2010, pp. $1-8$.

[27] H. Qin and J. W. Kimball, "Solid-state transformer architecture using AC-AC dual-active-bridge converter," in IEEE Transactions on Industrial Electronics, vol. 60, no. 9, pp. 3720-3730, Sept. 2013.

[28] X. Wang, J. Liu, T. Xu, and X. Wang, "Comparisons of different threestage three-phase cascaded modular topologies for power electronic transformer," in Proceedings of 2012 IEEE Energy Conversion Congress and Exposition (ECCE), Raleigh, NC, USA, Sept. 2012, pp. 1420-1425.

[29] D. Dujic, C. Zhao, A. Mester, J. K. Steinke, M. Weiss, S. LewdeniSchmid, T. Chaudhuri, and P. Stefanutti, "Power electronic traction transformer-low voltage prototype," in IEEE Transactions on Power Electronics, vol. 28, no. 12, pp. 5522-5534, Dec. 2013.

[30] T. Besselmann, A. Mester, and D. Dujic, "Power electronic traction transformer: Efficiency improvements under light-load conditions," in IEEE Transactions on Power Electronics, vol. 29, no. 8, pp. 3971-3981, Aug. 2014.

[31] J. Taufiq, "Power electronics technologies for railway vehicles," in Proceedings of 2007 Power Conversion Conference, Nagoya, Japan, 2007, pp. 1388-1393.

[32] C. Gu, Z. Zheng, L. Xu, K. Wang and Y. Li, "Modeling and control of a multiport power electronic transformer (PET) for electric traction applications," in IEEE Transactions on Power Electronics, vol. 31, no. 2, pp. 915-927, Feb. 2016.

[33] M. Glinka and R. Marquardt, "A new AC/AC multilevel converter family," in IEEE Transactions on Industrial Electronics, vol. 52, no. 3, pp. 662-669, Mar. 2005.

[34] C. Zhao, D. Dujic, A. Mester, J. K. Steinke, M. Weiss, S. LewdeniSchmid, T. Chaudhuri, and P. Stefanutti, "Power electronic traction transformer-Medium voltage prototype," in IEEE Transactions on Industrial Electronics, vol. 61, no. 7, pp. 3257-3268, Jul. 2014.

[35] R. Errouissi, A. AI-Durra, S. M. Muyeen, "Design and implementation of a nonlinear PI predictive controller for a grid-tied photovoltaic inverter," in IEEE Transactions on Industrial Electronics, vol. 64, no. 2, pp. 1241-1250, Feb. 2017

[36] R. Errouissi and A. AI-Durra, "Design of PI controller together with active damping for grid-tied LCL-filter systems using disturbance observer based control approach," in IEEE Transactions on Industry Applications, vol. 54, no. 4, pp. 3820-3831, Jul./Aug. 2018. 
[37] G. Tapia, A. Tapia, and J. X. Ostolaza, "Proportional integral regulator based approach to wind farm reactive power management for secondary voltage control," in IEEE Transactions on Energy Conversion, vol. 22, no. 2, pp. 488-498, Jun.2007.

[38] T. A. Naidu, S. R. Arya, and R. Maurya, "Multiobjective dynamic voltage restorer with modified EPLL control and optimized PI-controller gains," in IEEE Transactions on Industrial Electronics, vol. 34, no. 3, pp. 2182-2192, Mar. 2019.

[39] Standardization Administration of the People's Republic of China, Power Quality-Harmonics in Public Supply Network, GB/T 14549-1993, Beijing, China: Electr. Power Press, 1993.

[40] Standardization Administration of the People's Republic of China, Power Quality-Three-Phase Voltage Unbalance, GB/T 15543-2008, Beijing, China: Electr. Power Press, 2008.

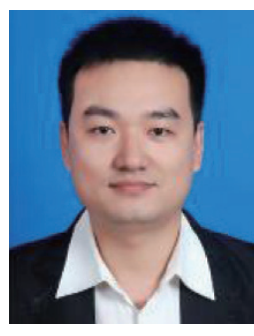

Peng Yao received his B.S. degree in electrical engineering from the Hunan Institute of Engineering, Xiangtan, China, in 2010, and the M.S. degree in control engineering from Hunan University, Changsha, China, in 2014.

He joined Zhuhai Wanlida Electrical Automation Co., Ltd. and Guangdong Province Voltage Sag Engineering Technology Research Center of Enterprise Power Supply \& Distribution System as an engineer from 2014, a deputy chief engineer in 2019. His current research interests include power quality control and power electronics.

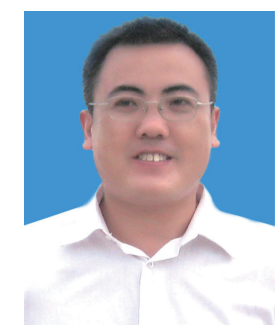

Zhiwei Zhu received his B.S. degree in Luoyang Institute of Technology, Luoyang, China, in 1998. He works at Zhuhai Wanlida Electrical Automation Co., Ltd. and Guangdong Province Voltage Sag Engineering Technology Research Center of Enterprise Power Supply \& Distribution System. His current research interests include energy-saving technology and power electronics. 